\title{
Interaction between granulin A and enolase 1 attenuates the migration and invasion of human hepatoma cells
}

\author{
Xiaoliang Chen ${ }^{1}$, Huanli $\mathrm{Xu}^{1}{ }^{1}$, Ning Wu${ }^{2}$, Xiujun Liu ${ }^{3}$, Gan Qiao ${ }^{1}$, Shuonan Su${ }^{1}$, \\ Ye Tian', Ru Yuan ${ }^{1}$, Cong Li ${ }^{1}$, Xiaohui Liu ${ }^{1}$, Xiukun Lin ${ }^{1}$ \\ ${ }^{1}$ Department of Pharmacology, Capital Medical University, Beijing 100069, China \\ ${ }^{2}$ Institute of Oceanology, Chinese Academy of Science, Qingdao 266003, China \\ ${ }^{3}$ Institute of Medicinal Biotechnology, Chinese Academy of Medical Science, Beijing 100050, China \\ Correspondence to: Xiukun Lin, email: xiukunlin@126.com
}

Keywords: enolase 1, granulin A, invasion, migration, protein-protein interaction

Received: December 23, $2016 \quad$ Accepted: March 06, $2017 \quad$ Published: March 17, 2017

Copyright: Chen et al. This is an open-access article distributed under the terms of the Creative Commons Attribution License (CC-BY), which permits unrestricted use, distribution, and reproduction in any medium, provided the original author and source are credited.

\section{ABSTRACT}

Granulin A (GRN A), a peptide with a molecular $6 \mathrm{kDa}$, is derived from proteolysis of progranulin (PGRN). Previous study in our laboratory has shown that GRN A is able to inhibit cancer cell growth significantly. In the present study, we confirmed that GRN A can bind to a-enolase (ENO1) specifically as analyzed using Pull-down/MS approaches. The interaction of GRN A with ENO1 was further confirmed by Western blotting and Surface plasmon resonance (SPR) analysis. Treatment of human HepG-2 cells with GRN A inhibited cancer cell growth as well as migration and invasion of cancer cells as analyzed by the 3-(4,5-dimethylthiazol-2-yl)-2,5-diphenyl tetrazoliumbromide (MTT) and Scratch wound healing assay as well as Transwell experiments. Additionally, GRN A treatment results in augmentation of glucose uptake in cancer cells. Further study reveals that higher expression of ENO1 reversed the inhibitory effects of GRN A on migration and invasion of HepG-2 cells. The increase of glucose uptake, as well as the expression of apoptosis-related genes, is also reversed in cells overexpressing ENO1. The study provides solid evidence that there is the interaction between GRN A and ENO1 and the interaction is responsible for the effects of GRN A on glucose uptake as well as cancer cell migration and invasion.

\section{INTRODUCTION}

Granulins (GRNs), also known as epithelins, are a family of about $6 \mathrm{kDa}$ peptides that derived from proteolysis of progranulin (PGRN). The GRNs family including GRN A, B, C, D, E, F, G, contain 12 cysteine residues with diverse functions [1-3]. It is well established GRNs play an important role in mammalian cell growth, acting as agonistic and antagonistic in cell development [4]. GRN A is initially found and purified from human leukocytes and rat bone marrow [5], and the peptide was confirmed to display proliferation inhibition on human epidermoid carcinoma A431 cells and breast cancer MDMBA-468 cells [6, 7]. Previous studies in our laboratory also revealed that GRN A induced cancer cell apoptosis in several human cancer cells [8]. However, the exact targets of the polypeptide are unknown and the underlying mechanism needed to be addressed.

Metastasis and invasion play critical roles in tumor malignancy and antimetastasis represents an important strategy on the treatment of cancer. Enolases, catalyzing the conversion of 2-phosphoglycerate (2-PG) to phosphoenolpyruvate (PK), besides its role in glycolysis, also play role in cancer metastasis. There are three different isoforms enolase; $\alpha$-enolase (ENO1), $\gamma$-enolase $(\mathrm{ENO} 2)$, and $\beta$-enolase (ENO3). ENO1 with a molecular weight of $48 \mathrm{kDa}$ is expressed in both the cytoplasm as well as cell membrane [9]. ENO1 is able to promote cell growth via FAK/PI3K/AKT pathway [10]. Recent study also shows that ENO1 activates pericellular plasminogen, resulting in accelerating degradation of the extracellular matrix and elevation of invasion and metastasis of tumor 
cells $[9,11]$. However, the regulation of ENO1 in cancer cells is not clear. In addition, ENO1 is usually overexpressed in tumor cells. Knocking down the expression of ENO1 results in suppression of cell growth, clone formation, and inhibition of the migration and invasion of cancer cells $[11,12]$. The enzyme is considered to be a promising target for the treatment of tumor.

In the present study, the targeted protein of GRN A was identified using pull-down/SDS-PAGE/LC-MS analysis. The interaction between GRN A and ENO1 was investigated using Western blotting and SPR analysis. The effect of GRN A on migration and invasion of cancer cells was studied using the Scratch wound healing assay and the Transwell assays. The underlying mechanism was further illustrated by checking the effect of GRN A on the expression of related proteins using Western blotting assay.

\section{RESULTS}

\section{GRN A inhibited the growth and induced cells apoptosis}

MTT assay was performed to evaluate the antiproliferative effects of GRN A against several cell lines. The results revealed that GRN A possessed a significant growthinhibition effect on cancer cell lines (Figure 1A). After treated with GRN A $(10 \mu \mathrm{M})$ in serum-free DMEM media for $72 \mathrm{~h}$, the relative inhibitory rate on PANC28, HepG-2, A431 were $71.83 \pm 0.96,73.59 \pm 3.64,62.47 \pm 13.46 \%$ respectively. Among these cell lines, HepG-2 cells were much more sensitive than that of the other cells lines with an IC50 value of $5.76 \mu \mathrm{M}$ (Figure 1B). In our next experiments, HepG-2 cells were selected for further study.

To further confirm GRN A induced apoptotic activity, flow cytometry analysis was performed using V-FITC /PI double-staining assay. The results revealed that a dose-dependent increase of total apoptotic cells was observed in cells treated with GRN A; the percentage of total apoptotic cells was $24.07 \%$ in untreated cells, whereas the percentages of total apoptotic cells were 42.14, 60.48, 95.96\% in the HepG-2 cells treated with 5, 10 and $20 \mu \mathrm{M}$ GRN A, respectively (Figure 1C ). The percentages of late apoptotic cells induced by GRN A at the concentrations of 5, 10 and $20 \mu \mathrm{M}$ were $34.57,52.97$ and $93.89 \%$, respectively. These results suggest that GRN A induces cell death via apoptotic pathway.

Western blotting analysis was performed to investigate the underlying mechanism regarding the GRN A induced cell apoptosis. The results showed that the expression of anti-apoptosis proteins, including $\mathrm{Bcl}-\mathrm{xL}$, AKT, c-Myc, were decreased in a dose-dependent manner in cells treated with GRNA. Meanwhile, the expression of PARP was also diminished, but the expression of cleavedPARP was increased (Figure 1D).

\section{Distribution of GRN A in HepG-2 cells}

The localization of GRN A was analyzed using Confocal imaging experiment. HepG-2 cells were treated without or with GRN A for $24 \mathrm{~h}$. The results showed that GRN A mainly located in the cell membrane in nonpenetrated analysis (Figure 2B). However, GRN A was also observed in both cell membrane and cytoplasm when treated with $0.1 \%$ triton X-100 (Figure 2D). These results suggested that GRN A was distributed in both the cell membrane and cytoplasm.

\section{ENO1 was identified as the molecular target interacted with the GRN A}

To begin identification of the molecular target of GRN A, we initially use Pull-down assay to identify the cellular target protein. Cells treated with or without GRN A were lysed and the lysates were incubated with His-resin. The absorbed proteins on the resins were eluted, and SDSPAGE analysis was performed to check the preyed proteins by the His-resins. As shown in Figure 3A, the preyed protein appeared obviously at the band with a molecular weight of about $50 \mathrm{kDa}$ and the protein was identified as ENO1 using LC-MS/MS analysis (Figure 3B, 3C).

To further confirm the interaction between GRN A and ENO1, Western blotting analysis was carried out. As shown in Figure 3D, the monoclonal His-antibody is able to bind toENO1 specifically. The interaction of GRN A and ENO1 was further investigated using SPR analysis. The results showed that the equilibrium dissociation constant KD value of ENO1 and GRN A was $56.04 \mu \mathrm{M}$ $\left(\mathrm{K}_{\text {off }}=0.01317 \mathrm{Ms}^{-1}, \mathrm{~K}_{\text {on }}=235.1 \mathrm{~s}^{-1}\right)$ (Figure 3E). These results further confirmed the interaction between ENO1 and GRN A.

\section{GRN A induced cellular glucose uptake}

Our results have confirmed that GRN A is able to interact with ENO1 specifically. In our next investigation, we try to dissect the function of the interaction between GRN A and ENO1. Recent study by Jung DW et al identified an ENO1 inhibitor, AP-III-a4 (Cas no. 117782773-4), called enoblock, which can bind with ENO1[13]. Paralleled experiments were performed to compare the effect of GRN A and enoblock on glucose uptake. The results showed that treatment of the HepG-2 cells with GRN A increased the glucose uptake significantly, similar with that of the cells treated with enoblock (Figure 4A, 4B). These results suggested that GRN A is able to induce glucose uptake, and served as an ENO1 inhibitor. To confirm the mechanism by which GRN A promotes glucose uptake, the expression of some key enzymes related to gluconeogenesis were tested. As shown in Figure 4C, the expression of phosphoenolpyruvate carboxykinase 1 (PCK1), and phosphoenolpyruvate 
carboxykinase 2 (PCK2) were decreased. However, there is no significant change on the expression of glucose-6phosphatase (G-6-pase). These results suggested that GRN A can increase the gluconeogenesis via inhibiting PCK1 and PCK2.

\section{GRN A inhibited cells migration and invasion}

Previous study has shown that ENO1 is related to cell invasion and migration via interacting with urokinasetype plasminogen activator (UPA), urokinase-type plasminogen activator receptor (UPAR), and plasminogen [9]. To determine if treatment of cancer cells with GRN A affected cell motility, the Scratch wound healing assay was performed. As shown in Figure 5A, compared with the control group, the migration was remarkably inhibited in cells treated with GRN A ( 1 or $2 \mu \mathrm{M}$ ). Transwell assay also indicated that treatment of the cancer cells with GRN A inhibited cell mobility (Figure 5B); the number of cells migrated to the opposite side were $378 \pm 28,297 \pm 35$, $210 \pm 13,146 \pm 17$, when treated the cells with GRN A at a concentration of $0,0.5,1.0,2.0 \mu \mathrm{M}$ respectively. Treatment of the cancer cells with enoblock (from 0 to $5 \mu \mathrm{M}$ ) also displayed similar results; cells migrated to the opposite side were $378 \pm 28,295 \pm 22,214 \pm 14,141 \pm 26$, when treated with enoblock at a concentration of $0,1.25,2.50,5.00 \mu \mathrm{M}$, respectively. Moreover, GRN A treatment also inhibited cancer cell invasion (Figure 5C) in a dose-dependent manner, and the number of cells invaded to the opposite side were $208 \pm 16,167 \pm 16,115 \pm 3,62 \pm 9$, when treated the cells with GRN A at a concentration of $0,0.5,1.0$, $2.0 \mu \mathrm{M}$ respectively. Similar results were also found when treating the cells with enoblock. These results confirmed that GRN A is able to interfere with the metastasis and inhibits migration and invasion of cancer cells.
A

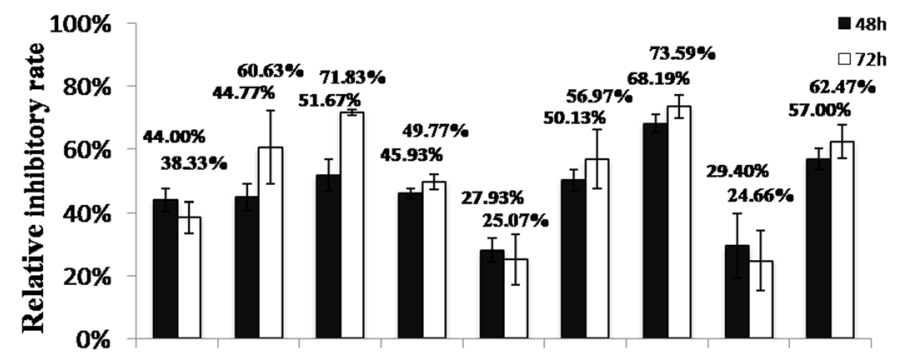

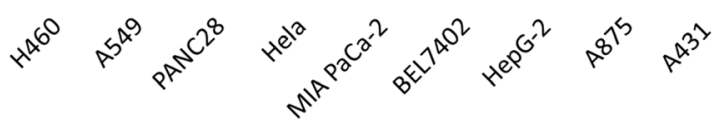

C
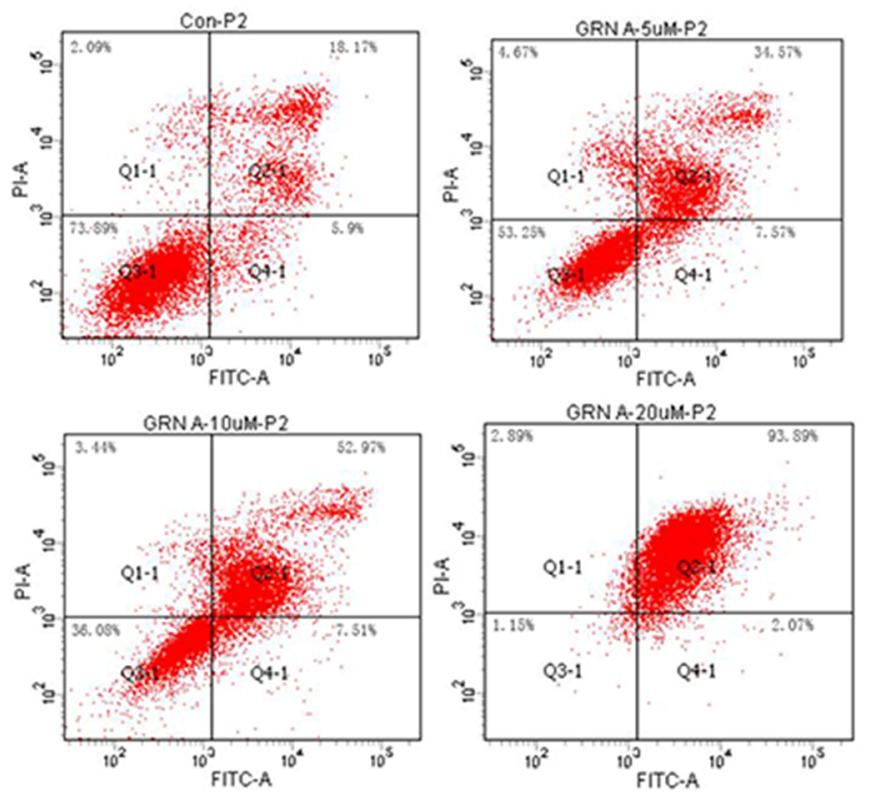

B

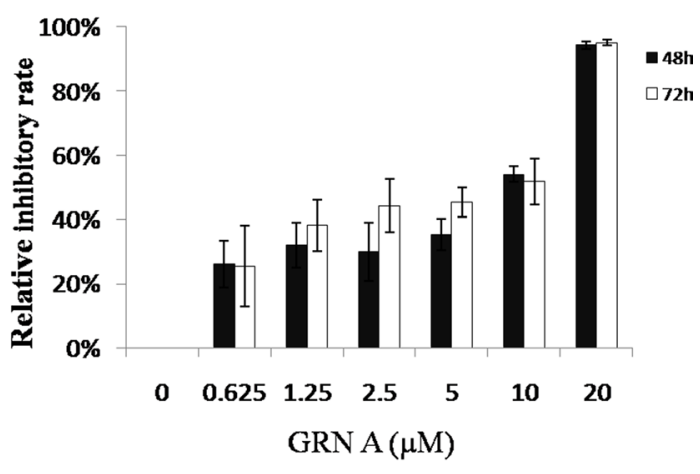

D

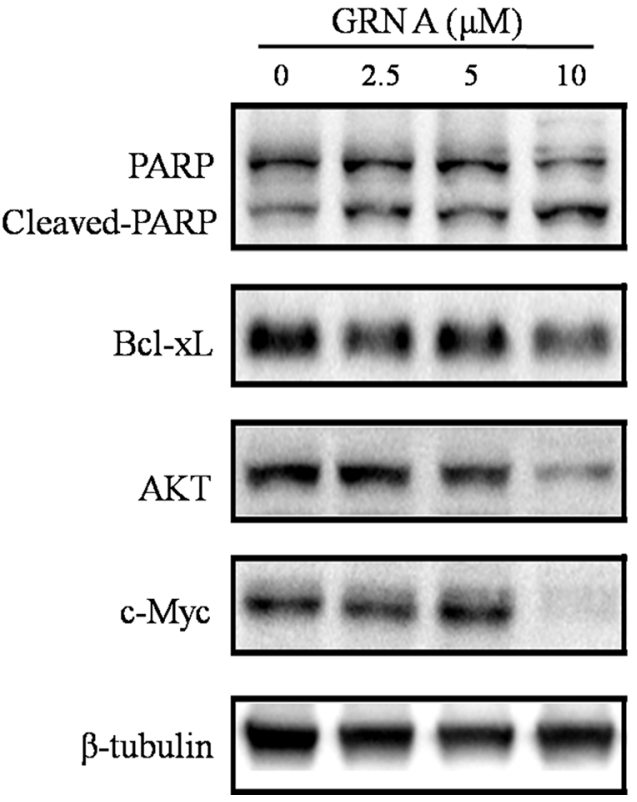

Figure 1: GRN A inhibited the growth and induced apoptosis in cancer cells. MTT assay was performed to determine the effect of GRN A on cell growth as described in Materials and Method section. The effect of GRN A on the growth of different cells was presented in (A), while (B) indicated a dose-dependent assay of GRN A on HepG-2 cells. (C) represented the GRN A on cell apoptosis as analyzed using flow cytometry. The expression of apoptosis related-proteins were shown in (D) as analyzed using Western blotting. 


\section{Overexpression of ENO1 promoted cell} migration and invasion and reversed the effects of GRN A in HepG-2 cells

To study if the inhibition of migration and invasion of GRN A is related to the targeted protein ENO1, we studied the effect of GRN A on cells over-expressing ENO1. As shown in Figure 6A, the migration cells number in HepG-2 cells transfected with ENO1 increased from $227 \pm 15$ to $427 \pm 49$ (Figure 6Aa, A6b), suggesting that ENO1 is capable of enhancing the ability of cell migration. Additionally, treatment with GRN A inhibited
DAPI

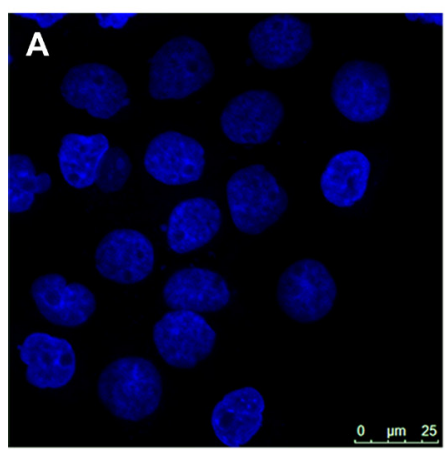

$\mathbf{B}$
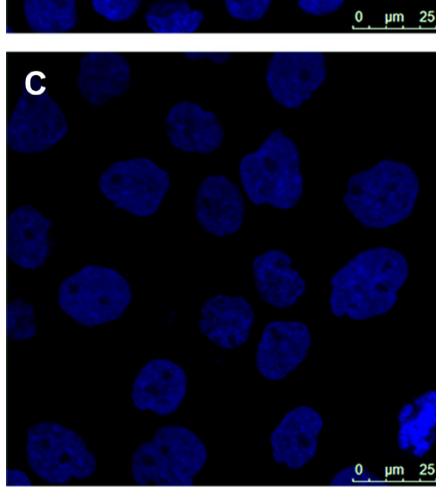

D
Anti-His tag
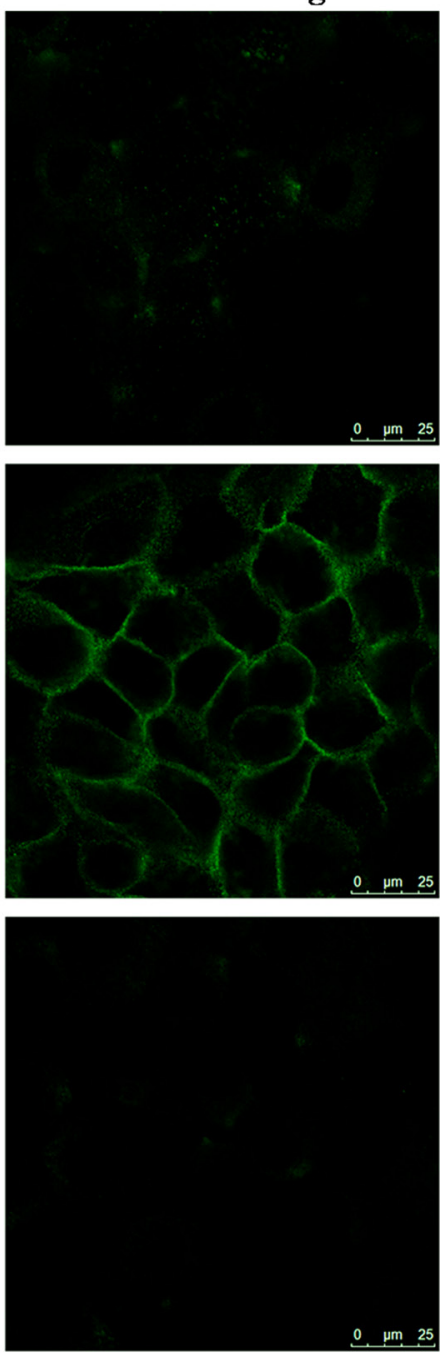

$\stackrel{0.25}{.25}$

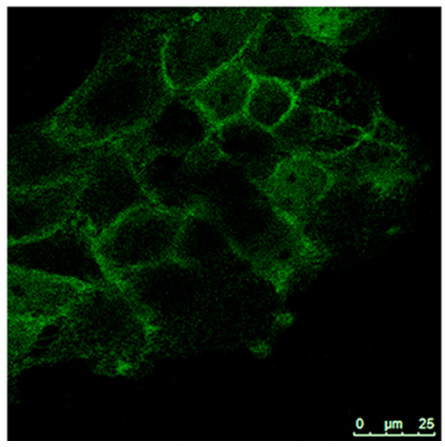

Merge
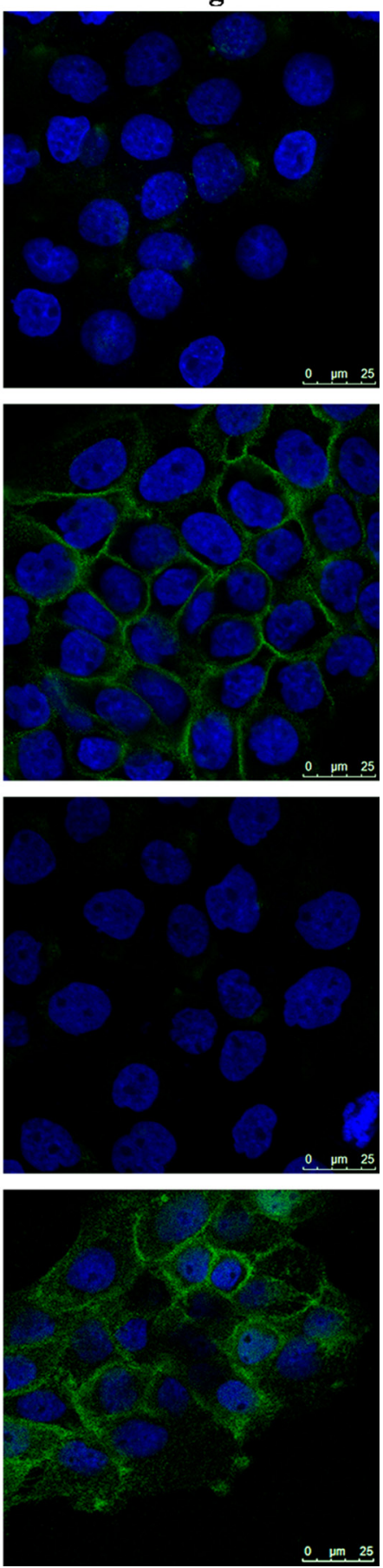

Figure 2: Distribution of GRN A in HepG-2 cells. The cells were cultured at $37^{\circ} \mathrm{C}$ for $24 \mathrm{~h}$ and treated without (A, C) or with (B, D) GRN A $(5 \mu \mathrm{M})$. After incubation for another $24 \mathrm{~h}$, cells were fixed with $4 \%$ paraformaldehyde and permeabilized with (C, D) or without (A, B) $0.1 \%$ triton X-100. The cells were further incubated with a mouse anti-His antibody overnight at $4{ }^{\circ} \mathrm{C}$. Subsequently, the cells were incubated with fluorescein isothiocyanate (FITC)-conjugated goat anti-mouse., and the cell image was observed using a Leica TCS SP8 confocal system (Leica microsystems, Germany). 
the cell migration significantly; the migration cells number decreased from $227 \pm 15$ to $144 \pm 21$ in cells transfected with control constructs (Figure 6Aa, 6Ac)). In contrast, overexpression of ENO1 reversed the effect of GRN A on migration of cancer cells; the number of migrated cells was increased to $346 \pm 46$ in ENO1 transfected cancer cells treated with GRN A, compared with that $(144 \pm 21)$ in cells transfected with the control plasmid (Figure 6Ac, 6Ad). Similarly, ENO1 overexpression attenuated the GRN A associated inhibitory effect of cell
A

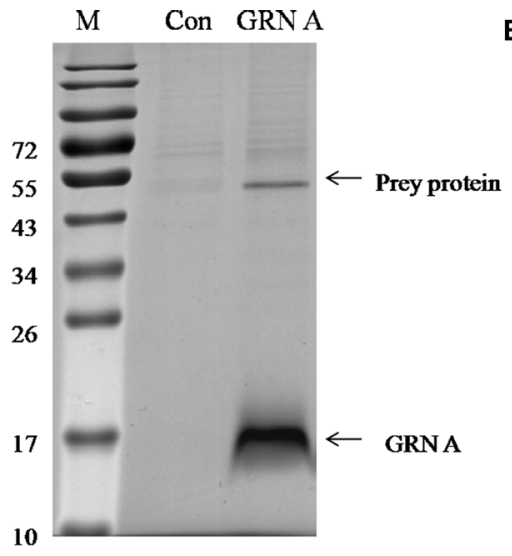

C

MSILKIHAREIFDSRGNPTVEVDLFTSKGLF RAAVPSGASTGIYEALELRDNDKTRYMGK GVSKAVEHINKTIAPALVSKKLNVTEQEKI DKLMIEMDGTENKSKFGANAILGVSLAVC KAGAVEKGVPLYRHIADLAGNSEVILPVPA FNVINGGSHAGNKLAMQEFMILPVGAA NFREAMRIGAEVYHNLKNVIKEKYGKDAT NVGDEGGFAPNILENKEGLELLKTAIGKA GYTDKVVIGMDVAASEFFRSGKYDLDFK SPDDPSRYISPDQLADLYKSFIKDYPVVSIE DPFDQDDWGAWQKFTASAGIQVVGDDL TVTNPKRIAKAVNEKSCNCLLLKVNQIGS VTESLQACKLAQANGWGVMVSHRSGET EDTFIADLVVGLCTGQIKTGAPCRSERLAK YNQLLRIEEELGSKAKFAGRNFRNPLAK

( Alpha-Enolase, SWISS-PROT: P06733, human )

B
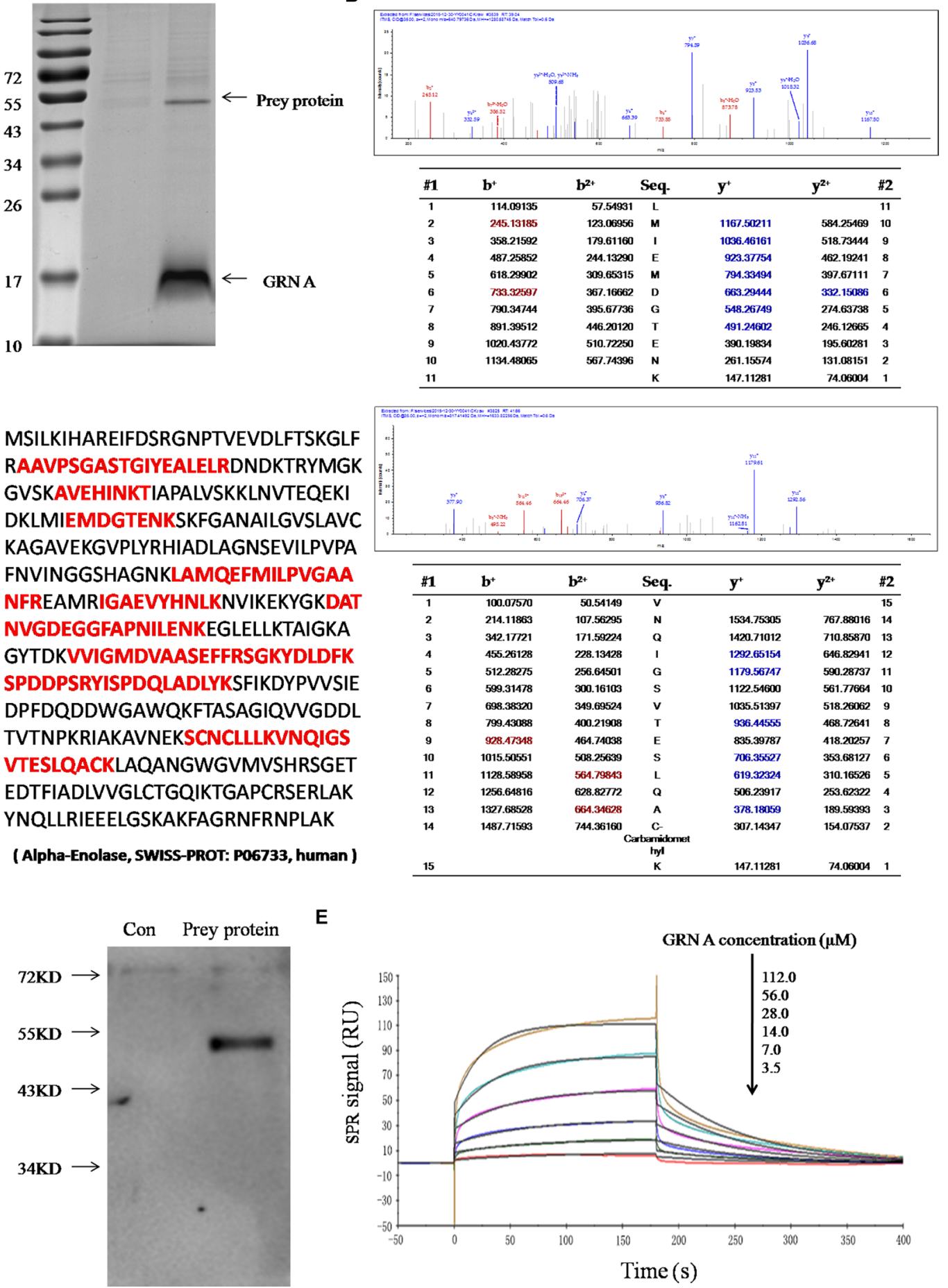

E

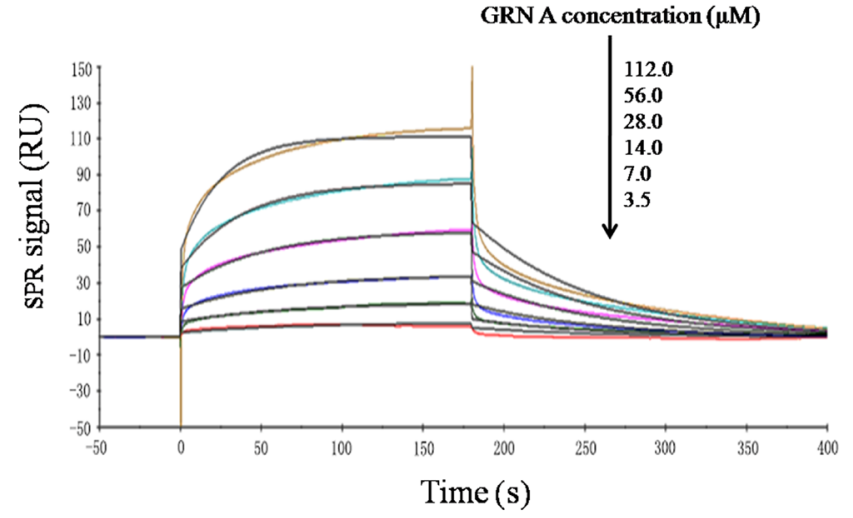

Figure 3: Interaction of GRN A with ENO1. (A) SDS-PAGE/His-pull down assay. SDS-PAGE/His-pull down assay was performed as described in the Materials and Method section. The prey protein band was indicated by an arrow. (B )Spectra of the prey peptide as analyzed by LC-MS/MS, which were identified as ENO1. (C) Amino acid sequence of ENO1. The red font represented the sequence analyzed by MS. (D) Western blotting analysis. The gel was immunoblotted using anti-ENO1 monoclonal antibody. (E) SPR analysis. The interaction of GRN A and ENO1 was analyzed using BIACORE T200. 
invasion. As shown in Figure 6B, the invaded cells number transfected with ENO1 increased from $123 \pm 7$ to $165 \pm 10$, indicating that ENO1 is able to promote the ability of cell invasion (Figure 6Ba, 6Bb)). In addition, treatment with GRN A inhibited the cell invasion significantly; the invasion cells number decreased from $123 \pm 7$ to $67 \pm 10$ (Figure 6Ba, 6Bc). However, overexpression of ENO1 reversed the effect of GRN A on migration of cancer cells significantly; the number of migrated cells was increased to $112 \pm 16$ in ENO1 transfected cancer cells treated with GRN A, compared with that in cells transfected with the control constructs (Figure 6Bc, 6Bd). These results suggested that the effect of GRN A on cell migration and invasion is associated with ENO1; overexpression of ENO1 promotes the cell migration and invasion.

\section{Overexpression of ENO1 enhanced the expression of apoptosis and glucose metabolic- related proteins}

We then studied if over-expression of ENO1 affects the expression of apoptosis proteins using Western blotting analysis. The results showed that the expression of antiapoptosis proteins, displayed opposite effects between normal HepG-2 cells and the cells over-expression of ENO1 when treated with GRN A; the expression of Bcl-xL and c-Myc are diminished significantly in cells treated with GRN A (Figure 1D). However, the expression of these genes was elevated significantly in cells over-expressing ENO1 (Figure 7A). The results indicated that GRN A induced cell apoptosis is associated with ENO1. Similar results were also found in gluconeogenesis proteins; GRN A treatment results in inhibition of the expression of PCK1 and PCK2 significantly (Figure 4C). However, these genes expression was enhanced obviously in cells over-

C

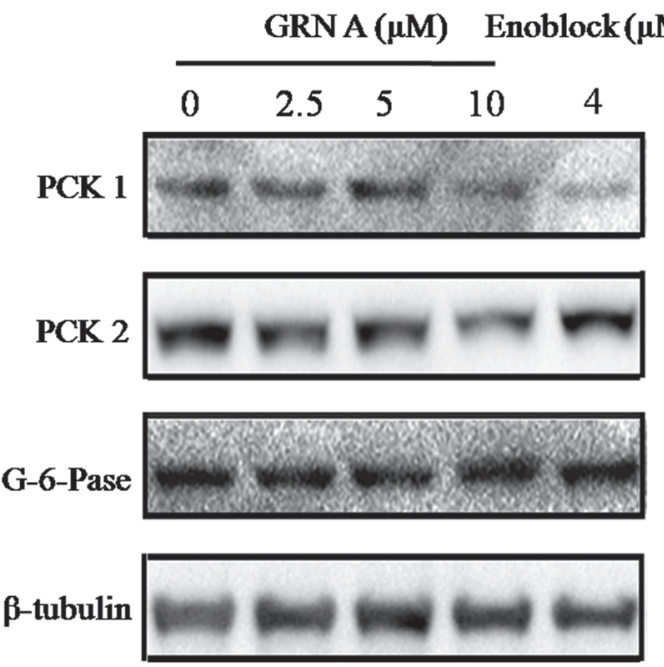

A
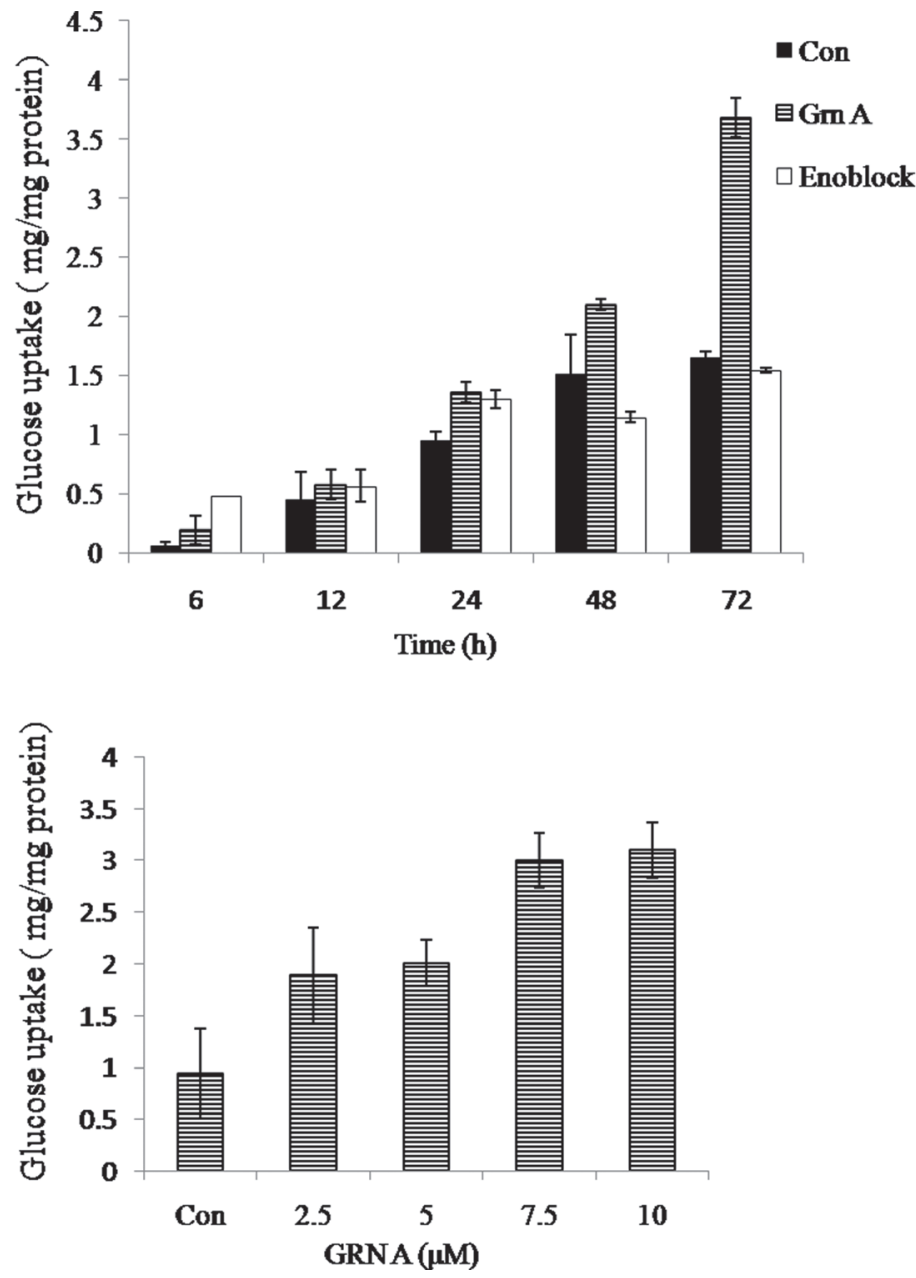

Figure 4: GRN A induced glucose uptake. Cell $\left(1 \times 10^{5}\right)$ was seeded in a $60 \mathrm{~mm}$ culture dish at $37^{\circ} \mathrm{C}$ for $24 \mathrm{~h}$, and then the cells were treated with or without GRNA $(5 \mu \mathrm{M})$ in $1 \%$ serum DMEM. The protein concentration and the levels of glucose uptake of the culture media were analyzed as described in Materials and Method section. (A) Effect of GRN A on cellular glucose uptake in HepG-2 cells. (B) Dosedependent effect of GRN A on cellular glucose uptake. (C) Western blotting analysis. Hepg-2 $\left(2 \times 10^{5}\right)$ was seeded in $60 \mathrm{~mm}$ culture dish at $37^{\circ} \mathrm{C}$ for $24 \mathrm{~h}$, and then the cells were treated with GRNA or enoblock for $48 \mathrm{~h}$. Related protein expression was determined by Western blotting analysis as described in Materials and Method section. 
expressing ENO1 (Figure 7B); suggesting that the effect of GRN A on glucose uptake is also associated with ENO1.

\section{DISCUSSION}

In the present report, we provide solid evidence that there is interaction between GRN A and ENO1; GRN A serves as an inhibitor of ENO1. Previous study has shown that an ENO1 inhibitor AP-III-a4, called enoblock, is able to bind with ENO1 and increase the glucose uptake significantly. Our present study also confirmed that similar as AP-III-a4, treatment of the cancer cells with GRN A also leads to enhancement of glucose uptake. Further study reveals that the GRN A inhibited gluconeogenesis is attributed to the inhibition of PCK1 and PCK2, and increased expression of ENO1 reverses the effect of GRN A on the expression of PCK1 and PCK2. We also found that GRN A is able to inhibit the enzymatic activity of ENO1; treatment of the ENO1 solution with $0.1 \mu \mathrm{M}$ GRN A results in $40 \%$ decrease of the enzymatic activity of ENO1 (data not shown). It is well known that gluconeogenesis plays an important role in maintaining blood glucose level, and the metabolism of glycogen as well as fatty acid. This study provides primary evidence that GRN A possesses potential to be developed as a novel
A
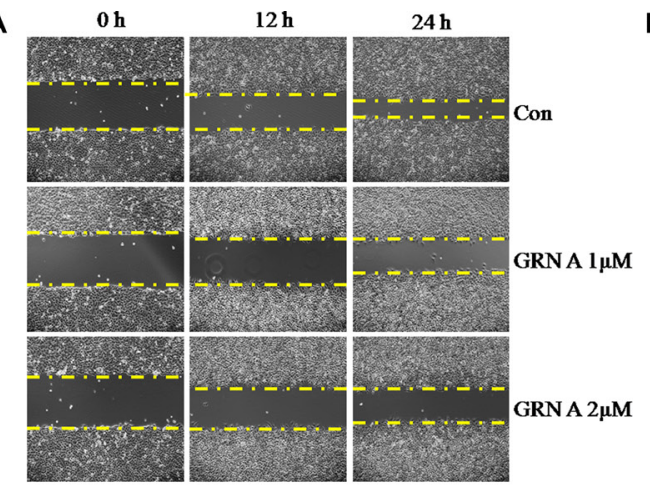

B

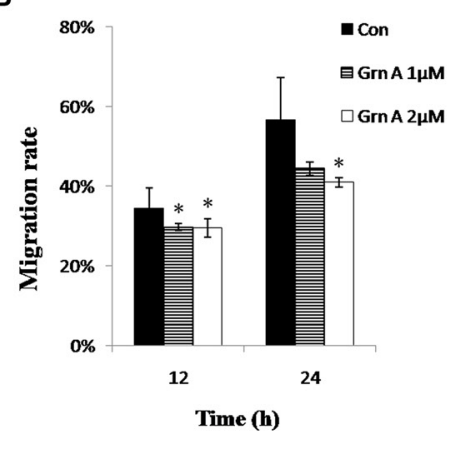

c
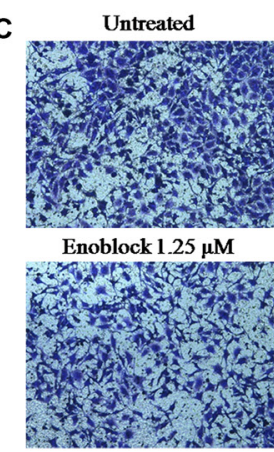

D

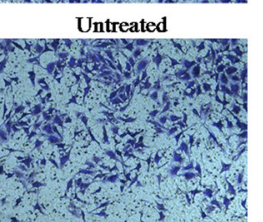

Enoblock 1.25 $\mu \mathrm{M}$
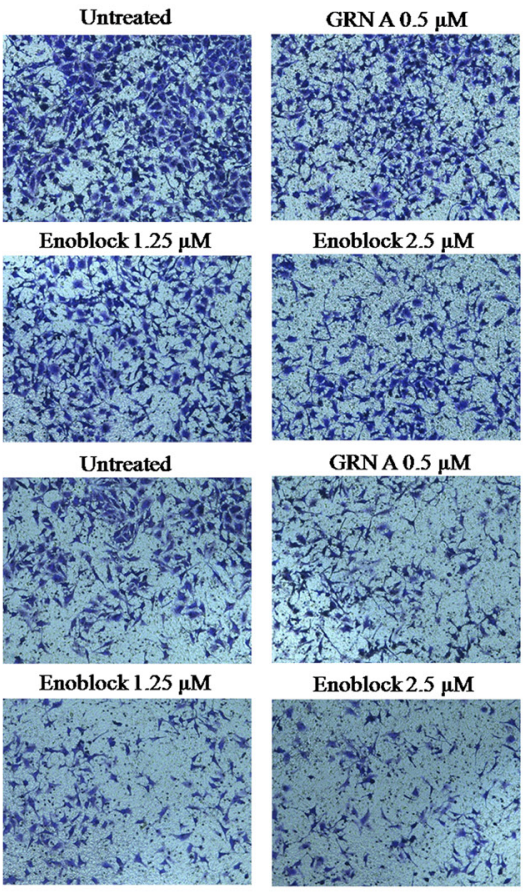

Enoblock $2.5 \mu \mathrm{M}$
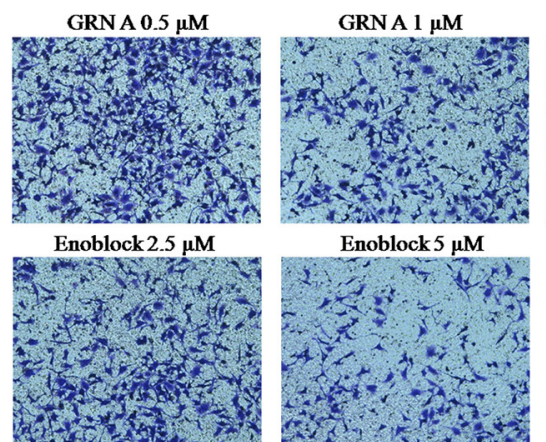

Enoblock $5 \mu \mathrm{M}$
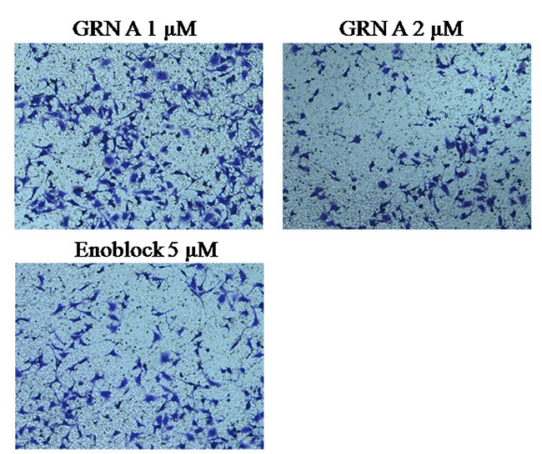

GRN A $0.5 \mu \mathrm{M}$

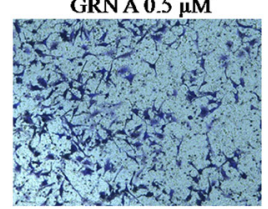

Enoblock $2.5 \mu \mathrm{M}$

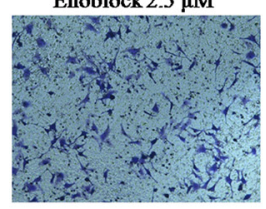

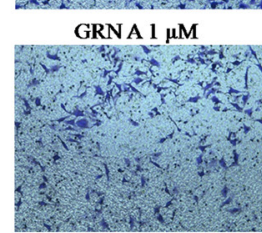

Enoblock $5 \mu \mathrm{M}$

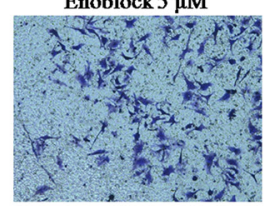

E
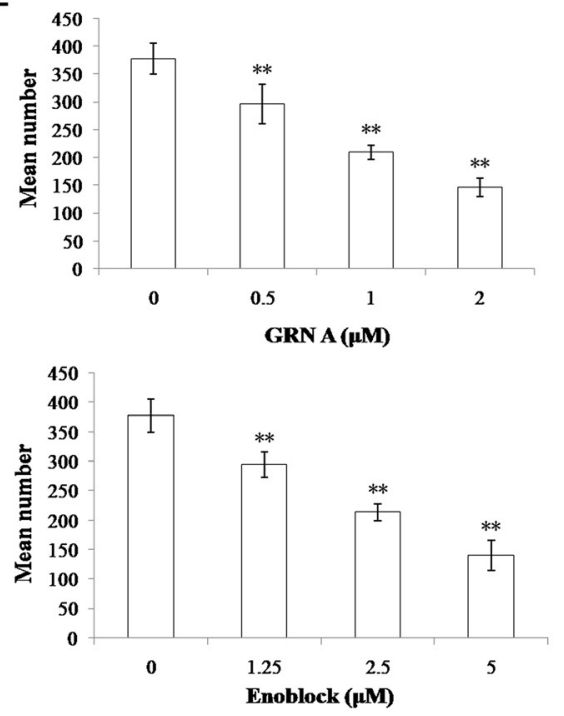

F
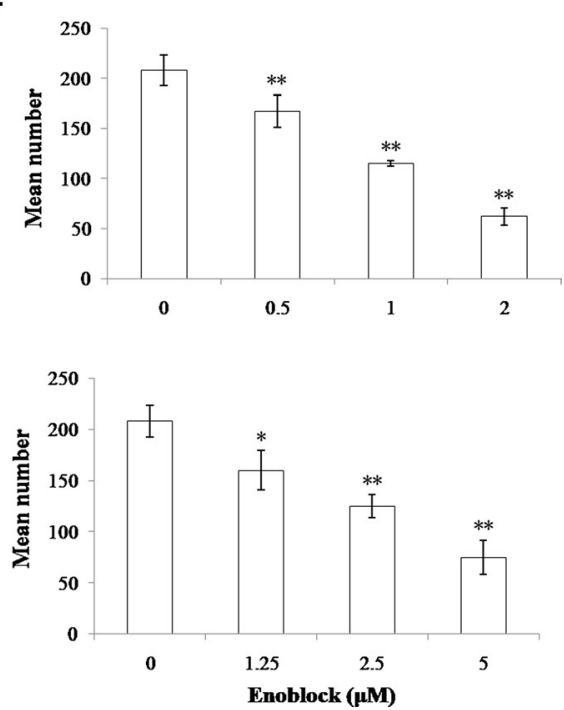

Figure 5: GRN A inhibited cells migration and invasion in HepG-2 cells. The effect of GRN A on cell migration and invasion was analyzed as described in Materials and Method section. Scratch wound healing assay was performed to determine the effect of GRN A on cell migration (A), while (B) is the quantitative result of Figure 5A. (C) and (D) represented the effect of GRN A on cell migration and invasion as determined using Transwell assay, while (E) and (F) indicated the quantitative result of Figure 5C, and 5D. The effect of enoblock on cell invasion was performed as a positive control. $n>3$ experimental repeats, ${ }^{*} p<0.05,{ }^{*} p<0.01$ versus control was considered significant. 
regulator of blood glucose level. Since the level of ENO1 is correlated with the expression of PCK1 and PCK2, targeting ENO1 may be a novel strategy for regulating the glucose metabolism. However, the detailed function of GRN A in gluconeogenesis needed to be further addressed.

Metastasis, a characteristic unique of cancer cells, includes multiple discrete steps; local migration, intravasation, circulating to the target organ, extravasation into target organ site, multiplication in target organ $[15,16]$. Migration and invasion of cancer cells result in the failure of standard chemotherapy and appearing to be inaccessible for irradiation or surgical treatment. Therefore, preventing invasion and metastasis of cancer cells is a promising strategy to develop novel anticancer agents. However, although a lot of antimetastasis agents have been found, no effective drugs are used clinically with good results [17]. Our present study showed that GRN A displays significant inhibition effects on migration and invasion of cancer cells. Since peptides from human cells display little immunogenicity, finding anticancer agents from human source is promising. Several peptides from human sources have been successfully used clinically for the treatment of human cancer, such as interferons and interleukins [18-20]. However, these kinds of peptides usually do not inhibit cancer cell growth directly; they affect the growth of tumors via an immune effect. In the present study, we found that the GRN A possesses the ability to inhibit proliferation of cancer cells directly. Furthermore, the peptide is also able to inhibit migration and invasion. This result provides primary evidence that GRN A has the potential to be developed as a novel kind of anticancer agent. In this study, we also confirmed that the inhibition effect of GRN A on cell migration and invasion depends on the interaction of GRN A and ENO1. This study also provides evidence that targeting ENO1 may be an important strategy to develop antimetastasis agents. Previous study also showed that ENO1 also functions as a plasminogen receptor; ENO1 can bind with plasminogen on the cell surface in a diverse of cells [9]. ENO1 was able to interact with uPA, and uPAR; resulting in augmentation of cell migration and invasion. More studies are needed to document if GRN A treatment of cancer cells is able to affect the interaction of ENO1 with plasminogen, uPA and uPAR.

Accumulative evidence reveals that in addition to its innate glycolytic functions, ENO1 plays important role in several biological and pathophysiological process; functioning as plasminogen receptor, playing role in myogenesis and muscle regeneration as well as in cell apoptosis etc [21], Higher expression of ENO1 is correlated with several kinds of cancer development $[11,12,14,22,23]$. However, the regulation of ENO1 is still not clear. Our study for the first time reveals that GRN $\mathrm{A}$ is able to interact with ENO1 and the interaction affects cell migration and invasion. The study reveals a novel regulation mechanism of ENO1; the function of ENO1 is regulated in part by GRN A. Studies are needed to address
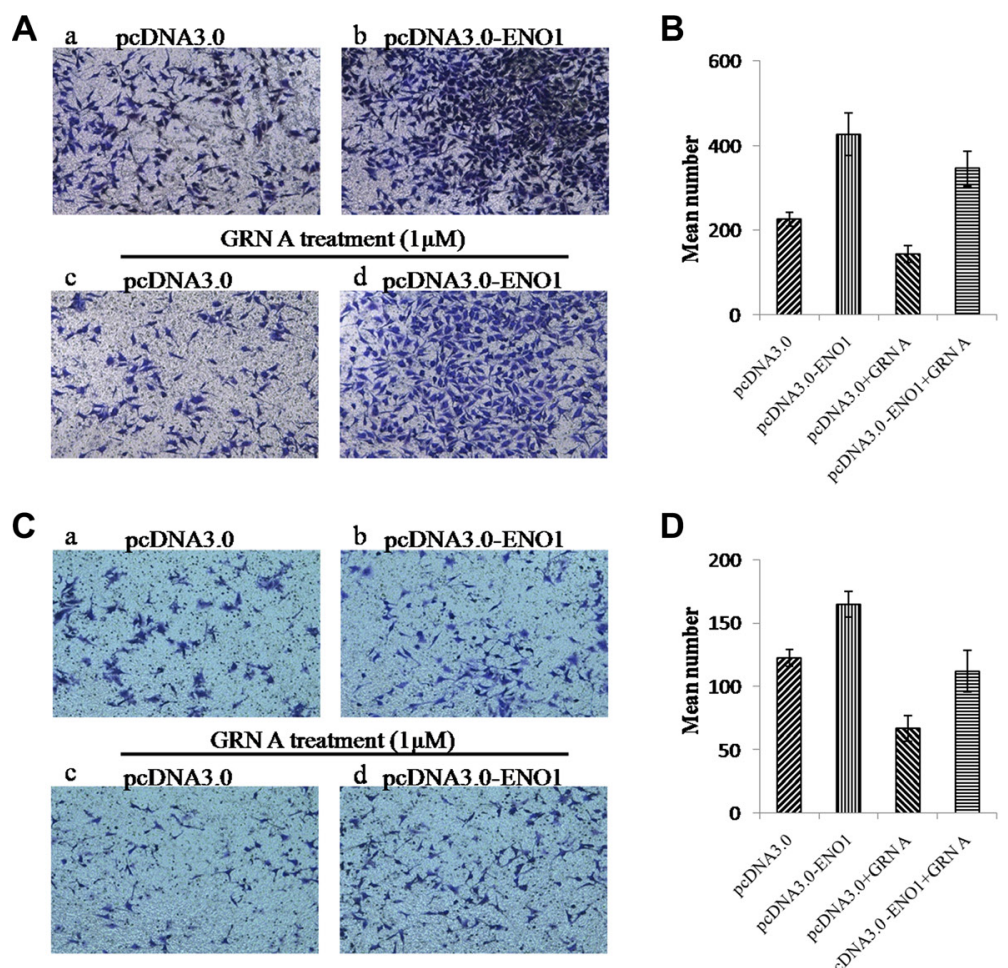

D

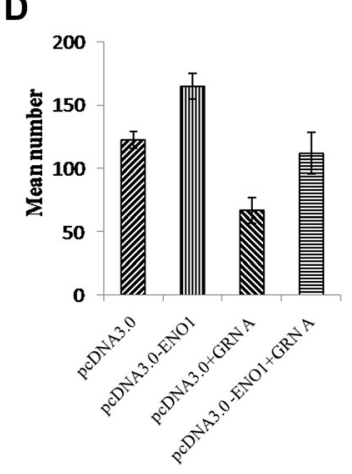

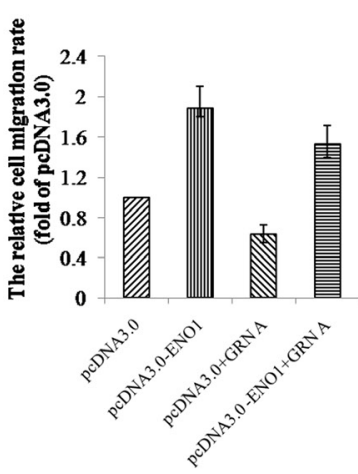

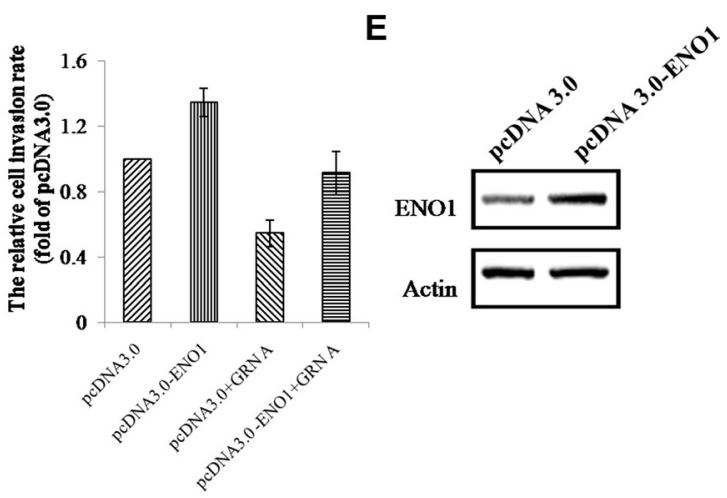

Figure 6: Overexpression of ENO1 reversed the effect of GRN A on cell migration and invasion. (A) and (B) indicated the migration and invasion in ENO1 overexpressing cells as analyzed using Transwell experiment, while (C and D) represented the quantitative results of (A) and (B). (E) indicated the levels of ENO1 in transfected with the ENO1 construct. 
if the interaction of GRN A and ENO1 affects the other functions of ENO1.

\section{MATERIALS AND METHODS}

\section{Cell culture}

The cell lines, including human lung carcinoma cells NCI-H460 and A549, human pancreatic cancer cells PANC-28, MIA PaCa-2, human cervical cancer Hela cells, human hepatoma cells BEL-7402 and HepG-2, human melanoma cells A875, human epidermoid carcinoma cells A431 were obtained from ATCC and were cultured in Dulbecco's modified eagle's medium (DMEM, Corning, NY) supplemented with $10 \%$ fetal bovine serum (FBS, Corning, NY), with $5 \% \mathrm{CO}_{2}$ at $37^{\circ} \mathrm{C}$.

\section{Antibodies}

Monoclonal antibodies; including rabbit anti-PCK1 (\#12940), rabbit anti-PCK2 (\#8586), rabbit anti-c-Myc (\#13987) and the polyclonal rabbit anti-PARP (\#9542) were purchased from Cell Signaling Technology (Danvers, MA). The monoclonal mouse anti-His-tag (\#ab18184), anti- $\beta$ actin (\#ab8229), anti-G-6-Pase (\#ab83690) and anti-ENO1 (\#ab112994) were purchased from Abcam (Cambridge, UK). The polyclonal rabbit anti-Bcl-xL (\#AB126) and the polyclonal rabbit anti-rabbit AKT (\#AA326) were obtained from Beyotime (Shanghai, China). The monoclonal mouse anti- $\beta$-tubulin (\#CW0098M) and fluorescein (FITC)conjugated affinipure goat anti-mouse IgG antibody (\#121217) were products of ComWin Biotech (Beijing, China) and Jackson ImmunoResearch Laboratories (West
Grove, PA) respectively.

\section{Cell cytotoxicity evaluation}

MTT assay was performed to evaluate the antiproliferative effects of GRN A against NCI-H460, A549, PANC-28, MIA PaCa-2, Hela, BEL-7402, HepG-2, A875 and A431 cells. Briefly, cells $\left(5 \times 10^{3}\right)$ were seeded in 96well culture plates and incubated at $37^{\circ} \mathrm{C}$ in humidified air atmosphere with $5 \% \mathrm{CO}_{2}$. After incubation for $24 \mathrm{~h}$, the cells were treated without or with certain concentrations of GRN $A$ in serum-free DMEM media. After cultured for another $48 \mathrm{~h}$ or $72 \mathrm{~h}$, MTT $(10 \mu \mathrm{L}, 5 \mathrm{mg} / \mathrm{mL}$, Sigma-Aldrich, St. Louis, MO) was added to each well and cells were incubated for an additional $4 \mathrm{~h}$. DMSO $(150 \mu \mathrm{L})$ was added to each well to dissolve the reduced MTT crystals. The MTT-formazan product dissolved in DMSO was estimated by measuring the absorbance at $570 \mathrm{~nm}$ with a micro plate reader (Biotech, power wave, USA). The percentage of cell growth inhibition was calculated as follows:

$$
\begin{aligned}
& \text { Relative inhibitory rate }(\%)=\left(\mathrm{OD}_{\text {control }}-\mathrm{OD}_{\text {treated }}\right) / \\
& \mathrm{OD}_{\text {control }} \times 100 \% \text {. }
\end{aligned}
$$

\section{Flow cytometry analysis}

Flow cytometry analysis was performed using Annexin V-FITC/PI apoptosis detection kit (\#KGA105, KeyGen, Nanjing, China) according to the manufacturer's protocol. Briefly, cells $\left(2 \times 10^{5}\right)$ were seeded in 6-well culture plates and incubated for $24 \mathrm{~h}$ at $37^{\circ} \mathrm{C}$. GRN A with certain concentration was directly added and incubated for an additional $48 \mathrm{~h}$. Then cells were harvested and resuspended in phosphate buffered saline (PBS). Apoptotic cells were examined by Epics-XL/MCL flow cytometer

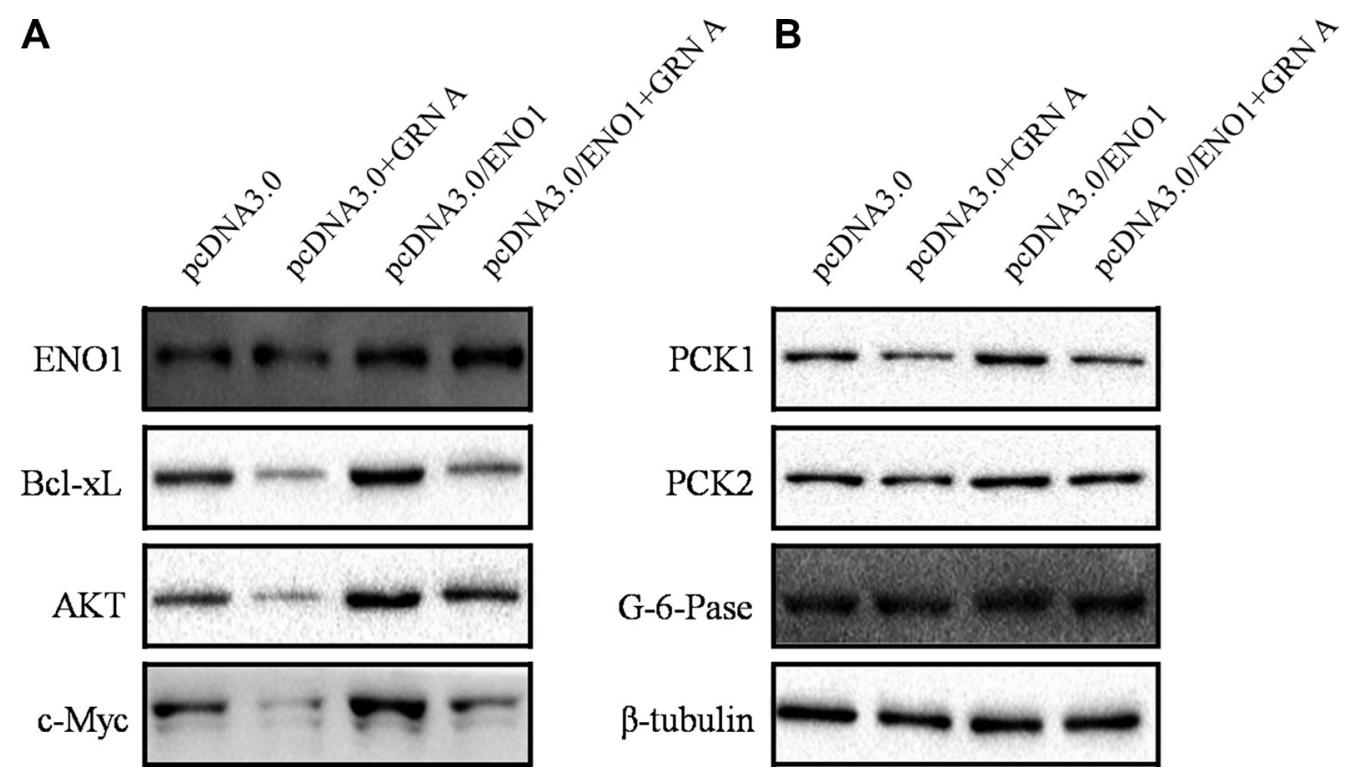

Figure 7: Overexpression of ENO1 enhanced the expression of apoptosis and glucose metabolic-related proteins. The expression of apoptosis proteins in cells overexpressing ENO1 was determined using Western blotting as described in Materials and Method section (A). The expression of gluconeogenesis-related protein in cells overexpressing ENO1 was presented in (B). 
(Beckman coulter, USA).

\section{Confocal imaging}

HepG-2 cells $\left(4 \times 10^{4}\right)$ were cultured on a $35 \mathrm{~mm}$ confocal dish (Corning, NY) and incubated at $37^{\circ} \mathrm{C}$. After incubation for $24 \mathrm{~h}$, the cells were treated without or with certain concentrations of GRN A. After cultured for another $24 \mathrm{~h}$, cells were fixed with $4 \%$ paraformaldehyde and permeabilized with or without $0.1 \%$ triton $\mathrm{X}-100$. The cells were further incubated with a mouse monoclonal anti-His-tag antibody overnight at $4^{\circ} \mathrm{C}$. Subsequently, the cells were incubated with FITC-conjugated goat antimouse IgG antibody. After incubation for additional $4 \mathrm{~h}$, 6-diamidino-2-phenylindole (DAPI) was added, and the cells were observed using a Leica TCS SP8 confocal system (Leica microsystems, Germany).

\section{Pull down assay}

Pull-down experiment was performed using the Pull-down polyHis protein: protein Interaction kit (\#21277, Pierce, IL) as per the manufacture's instruction. Briefly, HepG-2 cells $\left(2 \times 10^{5}\right)$ were cultured on a $60 \mathrm{~mm}$ culture dish and incubated at $37^{\circ} \mathrm{C}$ for $24 \mathrm{~h}$. The cells were released by trypsin digestion and washed with Tris-HCL buffered saline (TBS) and collected by centrifuging at $500 \times \mathrm{g}$ for $5 \mathrm{~min}$. The cells were resuspended in $2.5 \mathrm{~mL}$ of ice-cold TBS per gram wet weight of cells using a pipette. ProFound ${ }^{\mathrm{TM}}$ lysis buffer was added and mixed thoroughly on ice for $30 \mathrm{~min}$ and the lysate was collected by centrifugation at $12000 \times \mathrm{g}$ for $5 \mathrm{~min}$. Imidazole stock solution (4 M) was added to adjust imidazole to a final concentration of $20 \mathrm{mM}$. Cobalt chelate resin $(50 \mu \mathrm{L})$ was added into the spin column and equilibrated with washing solutions. Subsequently, the resin was incubated with or without $300 \mu \mathrm{L}$ of His-GRN A $(100 \mu \mathrm{g})$ at $4^{\circ} \mathrm{C}$ with gentle rocking. After incubated for $1 \mathrm{~h}$, the resins were collected by centrifugation at $1200 \times \mathrm{g}$ for $1 \mathrm{~min}$ and washed 5 times with TBS and incubated with the crude lysates of HepG-2 cells for $4 \mathrm{~h}$ at $4^{\circ} \mathrm{C}$. After washed with TBS for additional 5 times, the bound proteins in the resin were eluted with elution buffer (imidazole, $290 \mathrm{mM}$ ). The eluted sample was resolved using SDS-PAGE and visualized with Coomassie brilliant blue.

\section{Liquid chromatography-tandem mass spectrometry (LC-MS/MS) analysis}

The protein band stained with Coomassie blue was excised from the polyacrylamide gel and destained with $40 \%$ acetonitrile $/ 50 \mathrm{mM} \mathrm{NH}_{4} \mathrm{HCO}_{3}$. The gel pieces were dehydrated with $100 \%$ acetonitrile and reduced disulfide bonds with DTT $\left(10 \mathrm{mM}, 56^{\circ} \mathrm{C}, 45 \mathrm{~min}\right)$, and the free sulfhydryl groups were alkylated with iodoacetamide $\left(55 \mathrm{mM}, 25^{\circ} \mathrm{C}, 60 \mathrm{~min}\right.$ in the dark). The band was digested using enzyme solution $(100 \mathrm{ng} / \mu \mathrm{L}$ of trypsin in $25 \mathrm{mM}$ $\mathrm{NH}_{4} \mathrm{HCO}_{3}, \mathrm{pH} 8.3$ ) at $37^{\circ} \mathrm{C}$ overnight, and quenched with $60 \%$ acetonitrile containing $0.1 \% \mathrm{FA}$ and concentrated to $25 \mu \mathrm{L}$ using a speed vac.

The resulting tryptic peptides were reconstituted in HPLC using buffer A ( $0.5 \%$ formic acid water solution), loaded across a trap column (ReproSil-Pur C18-AQ, $0.15 \times 30 \mathrm{~mm}$, Dr. Maisch GmbH, Germany) at a flow rate of $0.2 \mu \mathrm{L} / \mathrm{min}$ and separated on a resolving analytical C18 column (ReproSil-Pur C18-AQ, $0.75 \times 150 \mathrm{~mm}$ ) with a linear gradient of buffer B from $4-80 \%(0.5 \%$ formic acid acetonitrile) at a flow rate of $300 \mathrm{~nL} / \mathrm{min}$. Eluted peptides were analyzed with nanoLC-LTQ-Orbitrap XL mass spectrometers (Thermo, San Jose, CA), and detected in the Orbitrap at a resolution of 60,000 . Eluted peptide cations were converted to gas-phase ions by Nanospray Flex ion source with $2.1 \mathrm{kV}$, and survey full scan MS spectra were acquired from $\mathrm{m} / \mathrm{z} 300$ to $\mathrm{m} / \mathrm{z} 1800$. The raw data was processed using Proteome Discoverer (version 1.4.0.288, Thermo Fischer Scientific).

\section{Western blotting assay}

Samples from pull-down assay were resolved in a $12 \%$ polyacrylamide gel and then transferred onto a PVDF membrane (Millipore, MA). After being blocked with $5 \%$ nonfat milk in TBS-T buffer $(20 \mathrm{mM}$ Tris, $137 \mathrm{mM}$ sodium chloride at $\mathrm{pH} 7.6,0.1 \%$ Tween-20) for $1 \mathrm{~h}$ at room temperature, membranes were incubated with primary antibody overnight at $4^{\circ} \mathrm{C}$. Horse radish peroxidase (HRP)-conjugated (ZSGBBIO, Beijing, China) secondary antibodies were used to detect the immunoreactivity by enhanced chemiluminescence (ECL) detection reagents (Applygen Technologies, Beijing, China).

Western blotting analysis was also performed to determine the expression of certain apoptotic related or glucose-metabolism related proteins in cells treated with or without GRN A. Briefly, HepG-2 cells were seeded into 6 well plates at a density of $2 \times 10^{5}$ cell $/$ well. After treated with or without GRN A for $48 \mathrm{~h}$, the cells were collected and lysed with cold RIPA buffer (\#R0278, Sigma-Aldrich, St. Louis, MO). The cell lysates were resolved on SDSPAGE and analyzed using Western blotting experiments.

\section{SPR interaction analysis}

ENO1 (\#ATGP0404, ATGen, Montevideo, Uruguay) was diluted in $10 \mathrm{mM}$ sodium acetate buffer at PH 5.0 and 8171 response units (RU) were directly immobilized on a CM5 biosensor chip (Biacore AB, Uppsala, Sweden). GRN A was sequentially diluted in HBS-EP buffer $(10 \mathrm{mM}$ HEPES, $150 \mathrm{mM} \mathrm{NaCl}, 3 \mathrm{mM}$ EDTA and 0.05\% (v/v) surfactant P20) and used as a mobile phase and injected over the protein surface with certain concentrations of GRN A $(3.5,7.0,14.0,28.0,56.0,112.0 \mu \mathrm{M})$ at rate of $30 \mu \mathrm{L} / \mathrm{min}$. The flow cell without immobilized protein was served as a 
non-specific binding control. Binding was monitored using a BIACORE T200 (GE Healthcare, Uppsala, Sweden). The parameters $\mathrm{K}_{\mathrm{D}}$ (equilibrium dissociation constant) was determined by the Biacore T200 evaluation software version 2.0 using the formulae: $\mathrm{K}_{\mathrm{D}}=\mathrm{K}_{\text {off }} / \mathrm{K}_{\text {on }}\left(\mathrm{K}_{\text {on }}=\right.$ association rate constant and $\mathrm{K}_{\text {off }}=$ dissociation rate constant)

\section{Measurement of the level of glucose uptake}

Intracellular glucose uptake levels were determined using a glucose assays kit (\#DIGL-100, BioAssay Systems, CA), according to the manufacturer's protocol. Briefly, HepG-2 cells $\left(1 \times 10^{5}\right)$ were cultured on a $60 \mathrm{~mm}$ culture dish and incubated at $37^{\circ} \mathrm{C}$ for $24 \mathrm{~h}$, and then the cells were treated with or without GRN A $(5 \mu \mathrm{M})$ in $1 \%$ serum DMEM. After incubation for 0, 6, 12, 24, 48 and $72 \mathrm{~h}$, the cells were harvested and washed with PBS, and then the cells were lysed with RIPA buffer and collected by centrifugation $(10000 \times \mathrm{g}$ for $20 \mathrm{~min})$. Total protein concentration in the supernatant was determined using BCA protein assay kit (\#P0012s, Beyotime, China). To determine the levels of glucose uptake, the culture media $(5 \mu \mathrm{L})$ were added into $500 \mu \mathrm{L}$ working solution. After heating for $8 \mathrm{~min}$, the sample was cooled down in cold water bath for $4 \mathrm{~min}$, the mixture samples $(200 \mu \mathrm{L})$ were transferred into a 96-well plate and the glucose uptake was determined by measuring the absorbance at $630 \mathrm{~nm}$ with a micro plate reader (Biotech, power wave, USA).

\section{Scratch wound healing assay}

HepG-2 cells were seeded in a 6-well plate. After grown to $100 \%$ confluence, wounds were made by scraping the monolayer of cells with a $200 \mu \mathrm{L}$ tip. GRN A with certain concentration was added and cultured for $0,6,12$, and $24 \mathrm{~h}$. The area between wound edges in each well was measured using a standard template placed on the image. The wounded area was determined using Image Pro Plus Software.

\section{Cancer cell invasion and migration assay}

Transwell assay was performed as described previously [24]. Briefly, HepG-2 cells $\left(2 \times 10^{4}\right)$ were seeded into the upper chamber of a 24-well Transwell chamber (\#3422, Corning, NY, ). An aliquot of $800 \mu \mathrm{L}$ culture medium supplemented with $10 \%$ FBS was added into the lower well of the chamber. After incubation for $4 \mathrm{~h}$, the cells were treated without or with certain concentrations of GRN A in DMEM media containing $1 \% \mathrm{FBS}$. After incubation for $48 \mathrm{~h}$, cells in the upper well were removed with a cotton swab. Cells that migrated into the lower well were washed with PBS, fixed in $4 \%$ paraformaldehyde and stained with $0.25 \%$ crystal violet. Cell migration was quantified by counting the migrated cells in microscopic fields (100X) per filter, and the mean value per filter was calculated from four replicate filters.
For Transwell invasion assay, the cells of the upper well of the transwell were coated with $50 \mu \mathrm{L}(1 \mu \mathrm{g} / \mathrm{mL})$ Matrigel (\#356234, BD, CA). The Matrigel was allowed to harden at $37^{\circ} \mathrm{C}$ in a $5 \% \mathrm{CO}_{2}$ incubator for $4 \mathrm{~h}$ and then HepG-2 cells $\left(2 \times 10^{4}\right)$ were seeded into the upper chamber of a 24-well Transwell chamber. The rest of the assay was performed as described above.

\section{Statistical analysis}

Statistical analyses were performed using the software Excel 2007 and SPSS 20.0. Results are expressed as mean $\pm \mathrm{SD}$. One-way analysis of variance followed by Tukey's multiple comparison test was used to determine statistical significances. Statistical significance was accepted for $* p<0.05$.

\section{Authors' contributions}

XLC, HLX and XKL designed the experiments. XLC, GQ, SNS, YT, RY, CL, XHL performed most experiments. XLC, XJL, XHL and XKL analyzed data; XJL and NW critically read the manuscript; XLC wrote the manuscript. All authors read and approved the final manuscript.

\section{ACKNOWLEDGMENTS}

We would like to thank Yin Yang for technical support in SPR.

\section{CONFLICTS OF INTEREST}

The authors declare that they have no competing interests.

\section{FINANCIAL SUPPORT}

This work was supported by National Innovative Drug Development Project of China (No.\#: 2014ZX09102043-001) and the 863 High Technology Project of China (No\#. 2014AA093503). The study was also supported in part by the Natural Science Foundation of China (No\#: 81302906, 81273550, 81573457, and 41306157), the Shandong Provincial Natural Science Foundation in China (No\#: ZR2014HQ031, ZR2011HQ027 and 2016GGD03015) and Zibo Development Program of Sci. \& Tech, in Shandong, China (No\#2016KJ100048).

\section{REFERENCES}

1. Bhandari V, Bateman A. Structure and chromosomal location of the human granulin gene. Biochem Biophys Res Commun. 1992; 188:57-63.

2. Bhandari V, Palfree RG, Bateman A. Isolation and sequence of the granulin precursor cDNA from human bone marrow 
reveals tandem cysteine-rich granulin domains. Proc Natl Acad Sci. 1992; 89:1715-1719.

3. Plowman GD, Green JM, Neubauer MG, Buckley SD, McDonald VL, Todaro GJ, Shoyab M. Ther epithelin precursor encodes two proteins with opposing activities on epithelial cell growth. J Biol chem. 1992; 267:13073-13078.

4. Tolkatchev D, Malik S, Vinogradova A, Wang P, Chen Z, Xu P, Bennett HP, Bateman A, Ni F. Structure dissection of human progranulin identifies well-folded granulin/epithelin modules with unique functional activities. Protein Sci. 2008; 17:711-724.

5. Bateman A, Belcourt D, Bennett H, Lazure C, Solomon S. Granulins, a novel class of peptides from leukocytes. Biochem Biophys Res Commun. 1990; 173:1161-1168.

6. Shoyab M, McDonald VL, Byles C, Todaro GJ, Plowman GD. Epithelins 1 and 2: isolation and characterization of two cysteine-rich growth-modulating proteins. Proc Natl Acad Sci USA. 1990; 87:7912-7916.

7. Culouscou JM, Carlton GW, Shoyab M. Biochemical analysis of the epithelin receptor. J Biol Chem. 1993; 268:10458-10462.

8. Wang X, Xu H, Chen X, Tian Y, Lin X. Cloning, expression and cytotoxicity of granulin A, a novel polypeptide contained in human progranulin. Biosci Trends. 2016; 10:181-187.

9. Hsiao KC, Shih NY, Fang HL, Huang TS, Kuo CC, Chu PY, Hung YM, Chou SW, Yang YY, Chang GC, Liu KJ. Surface a-enolase promotes extracellular matrix degradation and tumor metastasis and represents a new therapeutic target. PLoS One. 2013; 8:e69354.

10. Fu QF, Liu Y, Fan Y, Hua SN, Qu HY, Dong SW, Li RL, Zhao MY, Zhen Y, Yu XL, Chen YY, Luo RC, Li R, et al. Alpha-enolase promotes cell glycolysis, growth, migration, and invasion in non-small cell lung cancer through FAKmediated PI3K/AKT pathway. J Hematol Oncol. 2015; 8:22. doi: 10.1186/s13045-015-0117-5.

11. Liu KJ, Shih NY. The Role of Enolase in Tissue Invasion and Metastasis of Pathogens and Tumor Cells. J Cancer Mol. 2007; 3:45-48.

12. Zhao M, Fang W, Wang Y, Guo S, Shu L, Wang L, Chen Y, Fu Q, Liu Y, Hua S, Fan Y, Liu Y, Deng X, et al. Enolase-1 is a therapeutic target in endometrial carcinoma. Oncotarget. 2015; 6:15610-15627. doi: 10.18632/oncotarget.3639.

13. Jung DW, Kim WH, Park SH, Lee J, Kim J, Su D, Ha HH, Chang YT, Williams DR. A Unique Small Molecule Inhibitor of Enolase Clarifies Its Role in Fundamental Biological Processes. ACS Chem Biol. 2013; 8:1271-1282.
14. Pancholi V. Multifunctional alpha-enolase: its role in diseases. Cell Mol Life Sci. 2001; 58:902-920.

15. Coghlin C, Murray GI. Current and emerging concepts in tumor metastasis. J Pathol. 2010; 222:1-15.

16. Brooks SA, Lomax-Browne HJ, Carter TM, Kinch CE, Hall DM. Molecular interactions in cancer cell metastasis. Acta Histochem. 2010; 112:3-25.

17. Blazejczyk A, Switalska M, Chlopicki S, Marcinek A, Gebicki J, Nowak M, Nasulewicz-Goldeman A,Wietrzyk J. 1-methylnicotinamide and its structural analog 1,4-dimethylpyridine for the prevention of cancer metastasis. J Exp Clin Cancer Res. 2016; 35:1-13.

18. Jonasch E, Haluska FG. Interferon in oncological practice: review of interferon biology, clinical applications, and toxicities. Oncologist. 2001; 6: 34-55.

19. Gao W, Kumar S, Lotze MT, Hanning C, Pobbins PD, Gambotto A. Innate immunity mediated by the cytokine IL-1 homologue 4 (IL-1H4/IL-1F7) induces IL-12dependent adaptive and profound antitumor immunity. J Immunol. 2003; 170:107-113.

20. Hernandez-Alcoceba R, Poutou J, Ballesteros- Briones MC, Smedou C. Gene therapy approaches against cancer using in vivo and ex vivo gene transfer of interleukin-12. Immunotherapy. 2016; 8:179-198.

21. Díaz-Ramos A, Roig-Borrellas A, García-Melero A, LópezAlemany. A-enolase, a multifunctional protien: its role on pathophysiological situations. J Biomed Biotechnol. 2012; 2012: 156795

22. Song Y, Luo QS, Hao L, Zheng H, Que TS, Zhang XA. Alpha-enolase as a potential cancer prognostic marker promotes cell growth, migration, and invasion in glioma. Mol Cancer; 2014; 13:1-12.

23. Zhu X, Miao X, Wu Y, Li C, Guo Y, Liu Y, Chen Y, Lu X, Wang Y, He S. ENO1 promotes tumor proliferaion and cell adhesion mediated drug resistance (CAM-DR) in NonHodgkin's Lymphomas. Exp Cell Res. 2015; 335:216-223.

24. Wang H, Wei J, Wu N, Liu M, Wang C, Zhang Y, Wang F, Liu H, Lin X. Mere 15, a novel polypeptide from Meretrix meretrix, inhibits adhesion, migration and invasion of human lung cancer A549 cell via down-regulating MMPs. Pharm Biol. 2013; 51:145-151. 